\title{
A first-principles approach for treating wastewaters
}

\author{
Adriano Santana | Andreia S. F. Farinha | Aniela Zarzar Toraño | \\ Mahmoud Ibrahim | Himanshu Mishra ${ }^{(0)}$
}

Water Desalination and Reuse Center (WDRC), Division of Biological and Environmental Science and Engineering (BESE), King Abdullah University of Science and Technology (KAUST), Thuwal, Saudi Arabia

\section{Correspondence}

Himanshu Mishra, Water Desalination and Reuse Center (WDRC), Division of Biological and Environmental Science and Engineering (BESE), King Abdullah University of Science and Technology (KAUST), Thuwal

23955-6900, Saudi Arabia.

Email: himanshu.mishra@kaust.edu.sa

Funding information

KAUST, Grant/Award Number:

BAS/1/1070-01-01

\begin{abstract}
Numerous materials are employed for the removal of contaminants from wastewaters. However, the regeneration/reuse of these materials is still seldom practiced. Quantitative insights into intermolecular forces between the contaminants and the functional surfaces might aid the rational design of reusable materials. Here, we compare the efficacies of aliphatic $\left(\mathrm{C}_{8} \mathrm{H}_{18}\right)$, aromatic $\left(\mathrm{C}_{6} \mathrm{H}_{6}\right)$, and aromatic perfluorinated $\left(\mathrm{C}_{6} \mathrm{~F}_{6}\right)$ moieties at removing methylene blue $\left(\mathrm{MB}^{+}\right)$as a surrogate cationic dye from water. We employed density functional theory with an implicit polarizable continuum model for water to accurately determine the contributions of the solvent's electrostatics in the adsorption process. Our calculations pinpointed the relative contributions of $\pi-\pi$ stacking, van der Waals complexation, hydrogen bonding, and cation $-\pi$ interactions, predicting that $\mathrm{MB}^{+}$would bind the strongest with $\mathrm{C}_{6} \mathrm{~F}_{6}$ due to hydrogen bonding and the weakest with $\mathrm{C}_{8} \mathrm{H}_{18}$. Complementary laboratory experiments revealed that, despite the similar hydrophobicity of silica beads functionalized with $\mathrm{Si}-\mathrm{C}_{8} \mathrm{H}_{17}, \mathrm{Si}-\mathrm{C}_{6} \mathrm{H}_{5}$, and $\mathrm{Si}-\mathrm{C}_{6} \mathrm{~F}_{5}$ groups, as characterized by their water contact angles, the relative uptake of aqueous $\mathrm{MB}^{+}$varied as $\mathrm{Si}-\mathrm{C}_{6} \mathrm{~F}_{5}(95 \%)>\mathrm{Si}-\mathrm{C}_{6} \mathrm{H}_{5}$ (35\%) $>\mathrm{Si}-\mathrm{C}_{8} \mathrm{H}_{17}$ (3\%). This first principles-led experimental approach can be easily extended to other classes of dyes, thereby advancing the rational design of adsorbents.
\end{abstract}

\section{KEYWORDS}

adsorption, binding energy, intermolecular forces, non-covalent interactions, wastewater

\section{1 | INTRODUCTION}

The worldwide consumption of water has been steadily increasing to meet the needs of humanity. ${ }^{[1]}$ Freshwater resources are being unsustainably depleted to support agricultural and industrial sectors, and the situation is exacerbated by the ongoing climate change and pervasive land and water pollution. ${ }^{[2-4]}$ In this context, wastewater treatment serves the crucial purpose of water reuse and sustainable discharge into the environment. ${ }^{[5]}$ Additionally, recovering valuable materials and resources from wastewaters is a promising approach toward circular economy. ${ }^{[6-9]}$ Treatment methods for wastewaters depend on their source and contaminants, such as the removal of oil from produced water, ${ }^{[10]}$ the remediation of municipal waste with microorganisms, ${ }^{[11]}$ or the treatment of textile effluents with macromolecular dyes. ${ }^{[12]}$ Of these, we are interested in the removal of dyes from wastewaters generated in industries, such as textile, cosmetics, pulp and paper, food and beverages, packaging, paints, and pharmaceuticals. ${ }^{[12]}$ Over 100000 commercial dyes are known presently, ${ }^{[13]}$ with an annual consumption of $>7 \times 10^{8} \mathrm{~kg} / \mathrm{y} .{ }^{[14]} \mathrm{About} 5 \%$ to 
$10 \%$ of these dyes appear in the effluent streams of industrial wastewater and are discharged into the environment. ${ }^{[12,15]}$ Many of these dyes are potentially toxic and could lead to unintended effects. ${ }^{[12,13]}$ In response, traditional methods to remove dyes from wastewater include adsorption, ion exchange, oxidation, and coagulation/flocculation. ${ }^{[16]}$ Adsorption is the most common strategy due to its low cost, efficiency, and ease of operation. ${ }^{[12]}$ In fact, common "broad-spectrum" adsorbents for dyes include activated carbon, silica gels, fly ash, bentonite, and perlite. ${ }^{[12]}$ However, these adsorbents are not regenerated after usage and are subsequently disposed of as waste. ${ }^{[13]}$ This is because the design of adsorbents has largely been empirical and without consideration of intermolecular forces. Thus, there is a need for rationally designed reusable adsorbents for treating wastewaters.

The rational design of a reusable adsorbent requires a quantitative understanding of the intermolecular and surface forces between the target contaminants and the adsorbents, such as ion- $\pi$ interactions, ${ }^{[17]} \pi-\pi$ stacking, ${ }^{[18]}$ hydrogen bonding, ${ }^{[19]}$ and van der Waals interactions, ${ }^{[20,21]}$ among others. ${ }^{[19]}$ In fact, reusable adsorbents should bind contaminants with energies in the range of 5 to $\left.10 \mathrm{~kb}_{\mathrm{b}} T / \mathrm{mol}^{(3-6 \mathrm{kcal} \text { mol }}{ }^{-1}\right)$, which is not only strong enough to facilitate wastewater treatment, but also weak enough to facilitate adsorbent regeneration. ${ }^{\text {[21-24] }}$ We chose methylene blue $\left(\mathrm{MB}^{+}\right)$as our model system, because it is a common cationic dye that is employed in the paper and pulp industry (Figure 1A). ${ }^{[25]}$. As an adsorbate, $\mathrm{MB}^{+}$is quite "versatile": it can form hydrogen bonds ( $\mathrm{H}$-bond) with electronegative atoms such as $\mathrm{O}, \mathrm{N}$, and $\mathrm{F}$; it can accept electrons in $\pi-\pi$ stacks; it can participate in cation- $\pi$ interactions ${ }^{[17,26]}$ due to its cationic nature (Figure 1B); and it can also interact through van der Waals interactions. ${ }^{[27]}$ It has been produced on a mass scale since the late 19 th century, and it also serves a starting material for numerous azine dyes. ${ }^{[25]}$ Its molecular versatility is further evidenced by its medical use to treat depression, ${ }^{[28]}$ breast cancer, ${ }^{[29]}$ malaria, ${ }^{[30]}$ Alzheimer's, ${ }^{[31]}$ and aging of the skin. ${ }^{\left[{ }^{32]}\right.}$ Yet, quantitative insights into the factors and mechanisms governing the adsorption of $\mathrm{MB}^{+}$even onto simple surfaces remain unclear. For example, it has been suggested that dispersion interactions and hydrophobic interactions are important in the adsorption of $\mathrm{MB}^{+}$onto metals $^{[27,33]}$ and silver iodide (Agl) suspensions, ${ }^{[33]}$ respectively, but a direct comparison of those interactions remains unavailable. Here, we utilize quantum mechanical calculations to predict binding energies of a hydrated $\mathrm{MB}^{+}$cation with a broad range of aliphatic, aromatic, and perfluorinated aromatics as surrogates for adsorbents (Figure 2). Subsequently, we test these predictions through laboratory experiments using silica microspheres terminated with the same aliphatic, aromatic, and perfluorinated aromatic groups.

\section{2 | MATERIALS AND METHODS}

\subsection{Quantum mechanical calculations}

Density functional theory (DFT) is a first-principles approach for predicting the electron density of molecular/ionic systems, which employs a selfconsistent field approach (SCF) for solving the Schrödinger equation. ${ }^{[34,35]}$ It has been used extensively for electronic structure calculations in solid-state physics and materials science. ${ }^{[24,36-39]}$ The accuracy of DFT in studying the electronic and physical properties of materials is largely dependent on the choice of the exchange-correlation function. For example, the local density approximation (LDA) and the generalized gradient approximation (GGA) exchange-correlation functionals overestimate the dissociation energies and the hydrogen bonds, respectively, ${ }^{[38]}$ and they require a dispersion energy correction when modeling van der Waals interactions or studying water clusters. ${ }^{[39]}$ Hybrid functionals such as B3LYP ${ }^{[40]}$ provide a good example of hydrogen bonding, ${ }^{[41,42]}$ the structure of water clusters, ${ }^{[43,44]}$ chemistries at the air-water interface, ${ }^{[45-49]}$ graphene-based systems, ${ }^{[50]}$ guest-host binding of $\mathrm{p}$-xylylenediamine to $\mathrm{CB} 7,{ }^{[51]}$ vibrational spectra of hexafluorobenzene, ${ }^{[52]}$ and $\pi-\pi$ interactions in dimers of benzene and napthalene. ${ }^{[18]}$ It should be noted that the accuracy of a DFT method crucially depends on the specific details of the molecular system. ${ }^{[53,54]}$ Here, we applied the B3LYP-level DFT to investigate the molecular interactions of $\mathrm{MB}^{+}$with hexafluorobenzene $\left(\mathrm{C}_{6} \mathrm{~F}_{6}\right)$, benzene $\left(\mathrm{C}_{6} \mathrm{H}_{6}\right)$, and n-octane $\left(\mathrm{C}_{8} \mathrm{H}_{18}\right)$ groups (Figure 2). We accounted for the aqueous environment utilizing the Polarizable Continuum Model (PCM). ${ }^{[55]}$ We chose these groups as surrogates for functional surfaces to gain insights into the vast array of molecular interactions of $\mathrm{MB}^{+}$

(A)

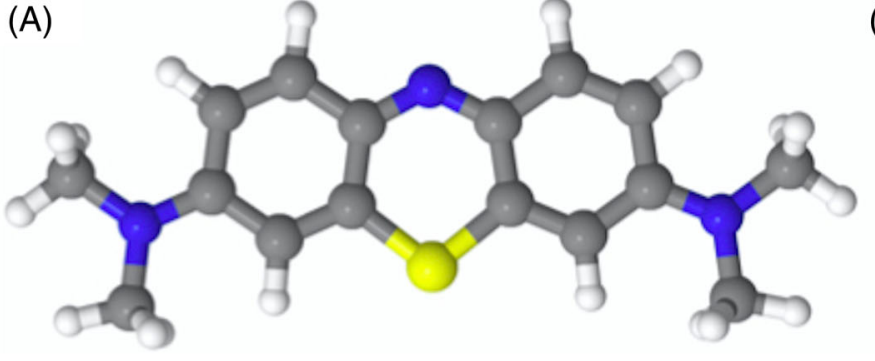

(B)

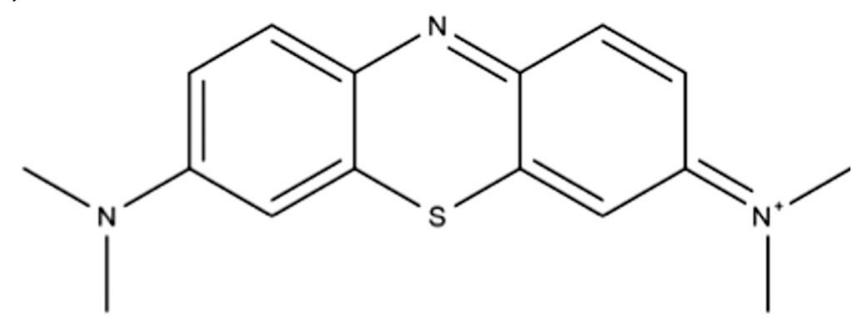

FIGURE 1 A, A two-dimensional diagram of a methylene blue molecule. Color scheme: sulfur in yellow, nitrogen in dark blue, hydrogen in white, and carbon in gray. $\mathrm{B}$, The Lewis structure of an $\mathrm{MB}^{+}$cation with the positive charge on the quaternary ammonium 
in an aqueous environment. We optimized numerous dimer conformations using DFT implemented in the Gaussian software ${ }^{[56]}$ at the B3LYP/6-311+G* level. ${ }^{[40]}$ For the most difficult convergence cases, as a result of encountering a shallow minima around the stationary point, we employed the option MaxStep = 1 that led to full convergence. We subsequently confirmed the stability of the optimized structures through frequency calculations at each stationary point.

\subsection{Experimental: Synthesis of hollow silica microspheres}

To test the quantum mechanical predictions, we perfromed laboratory experiments. We used commercially available hollow silica microspheres (3M Glass Bubbles) ${ }^{[57]}$ with an average diameter ranging from 16 to $65 \mu \mathrm{m}$ (Figure S1A). We modified their surface make-up following a two-step reaction, comprising of hydroxylation and silanation (Figure S1B). ${ }^{[58]}$ To hydroxylate the microspheres, we exposed them to an aqueous solution of hydrochloric acid $\left(\mathrm{pH}^{2}\right.$ 2) at $90^{\circ} \mathrm{C}$ for 1 hour (Data S1). Next, batches of microspheres were silanized using (i) triethoxy(octyl)silane, (ii) trimethoxyphenylsilane, and (iii) (pentafluorophenyl)triethoxysilane, all of which were obtained from Sigma-Aldrich (CAS: 2943-75-1, 2996-92-1, and 20 083-34-5, respectively). This protocol produced silica microspheres terminated with $\mathrm{Si}-\mathrm{C}_{8} \mathrm{H}_{17}, \mathrm{Si}-\mathrm{C}_{6} \mathrm{~F}_{5}$, and $\mathrm{Si}-\mathrm{C}_{6} \mathrm{H}_{5}$ groups, which we confirmed using FTIR spectroscopy (Figure S2, Data S1). ${ }^{[59]}$ Methylene blue was obtained from Sigma-Aldrich (CAS: 122965-43-9) in the quaternary ammonium salt form $\left(\mathrm{C}_{16} \mathrm{H}_{18} \mathrm{ClN}_{3} \mathrm{~S} \cdot \mathrm{xH}_{2} \mathrm{O}\right.$, molecular $319.85 \mathrm{~g} / \mathrm{mol}$ [anhydrous basis]). We incubated different amounts of functionalized $\mathrm{SiO}_{2}$ microspheres $(0-100 \mathrm{mg}$ ) in aqueous solutions containing $100 \mathrm{ppm} \mathrm{MB}$. Subsequently, the solutions were tumbled gently for 5 minutes. The separation was easy, because the hollow microspheres floated up to the air-water interface; a general scheme for adsorption is shown in Figure 3. To characterize the concentration of $\mathrm{MB}^{+}$in aqueous solutions before and after adsorption, we took aliquots, diluted them with deionized water, and characterized the concentration of $\mathrm{MB}^{+}$spectrophotometrically using its extinction coefficient at $663 \mathrm{~nm}$ (Data S2). Note: the optical attenuation of light through our solutions followed the Beer-Lambert law; the experiments were repeated at least in quadrupicates.

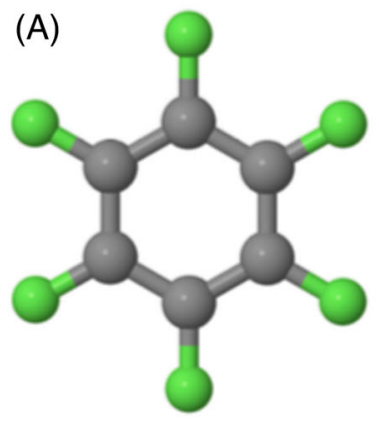

(B)

(C)
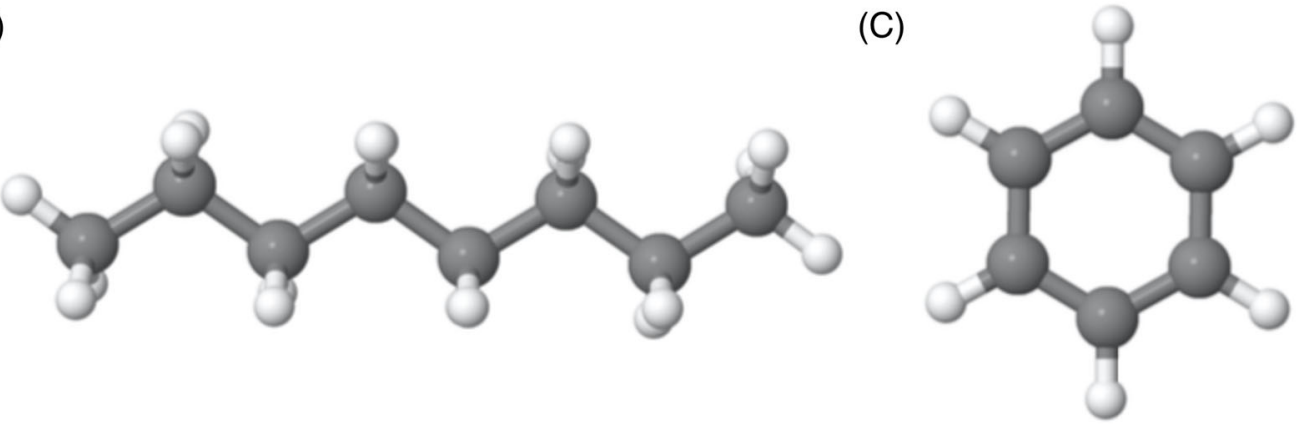

FIGURE 2 Ball-and-stick diagrams of: A, hexafluorobenzene; B, octane; and C, benzene. Color scheme: carbon atoms (gray), fluorine (green), and hydrogen (white)

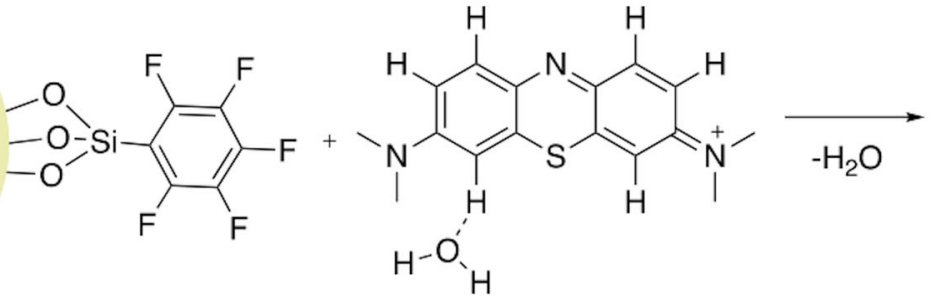

FIGURE 3 A general scheme for the adsorption of $\mathrm{MB}^{+}$onto functionalized silica microspheres. The hydrated methylene blue cation is considered with an explicit coordination water molecule. During adsorption, the adsorbent displaces this water molecule to bind with $\mathrm{MB}^{+}$.

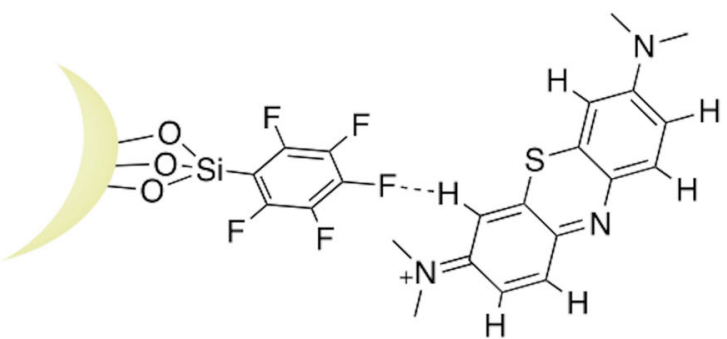




\section{RESULTS AND DISCUSSION}

\subsection{Methylene blue in solution}

We calculated the molecular electrostatic potential (ESP) of hydrated $\mathrm{MB}^{+}$, which is defined as the amount of work required to bring a positive unit charge from infinity to a distance $r$ from the molecule. ${ }^{[60,61]}$ Thus, ESP comprises the contributions of the nuclear and the electronic charges, the latter calculated by methods such as Mulliken population analysis and Löwdin population analysis. ${ }^{\text {[62] }}$ We mapped the electron density (chosen with a value of $\rho=0.02$ ) onto the electrostatic potential to obtain the ESP. ${ }^{[62]}$ The electron density was obtained from a Mulliken population analysis ${ }^{[60]}$ of the optimized DFT structure of $\mathrm{MB}^{+}$in an aqueous environment using the GaussView software (v. 5.0) ${ }^{[63]}$ (Figure 4A). Hydrated $\mathrm{MB}^{+}$has a positive ESP due to the overall electron charge deficiency of the cation, with the hydrogen atoms being the most positive (blue color) due to their low electronegativity. Thus, $\mathrm{MB}^{+}$can potentially participate in hydrogen bonding through these $\mathrm{H}$ atoms by accepting electrons in $\pi-\pi$ stacking, such as from benzene. The $\mathrm{N}$ and $\mathrm{S}$ atoms in the central ring (yellow color) behave neutrally toward electrophile/nucleophile molecules. The region between the $\mathrm{C}=\mathrm{C}$ double bonds and the two tertiary nitrogen atoms also shows low electron densities (light blue color), albeit more than for the $\mathrm{H}$ atoms. We qualitatively infer from the ESP plot that $\mathrm{MB}^{+}$potentially participates in hydrogen bonding, as well as $\pi-\pi$ stacking and cation $-\pi$ interactions.

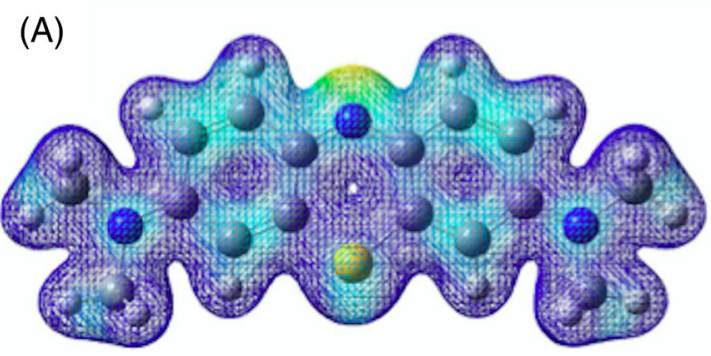

(C)

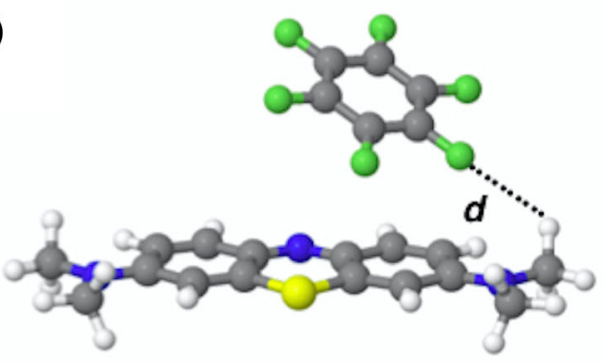

(E)

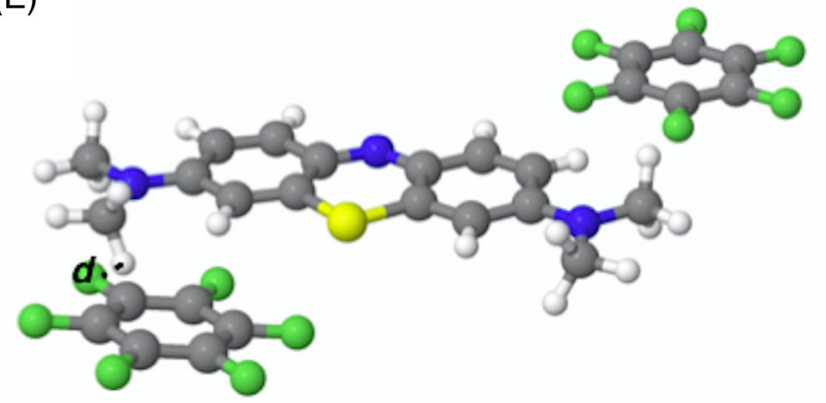

(B)
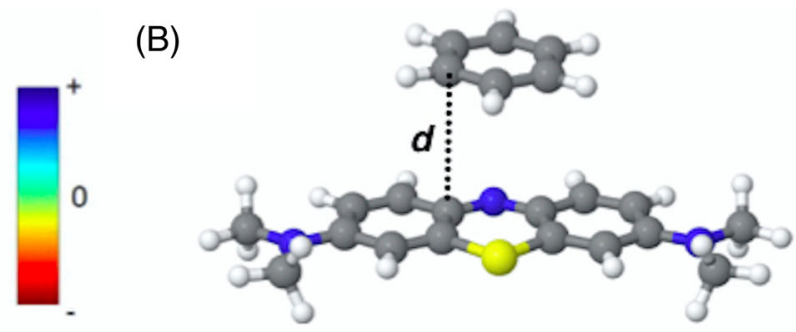

(D)

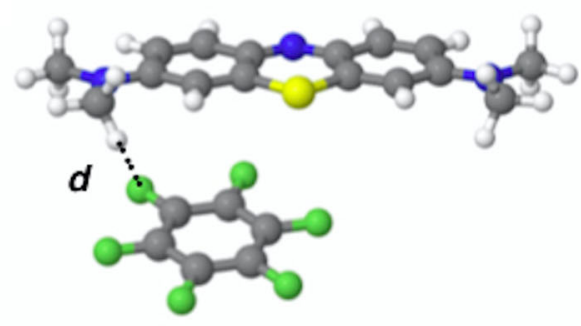

(F)

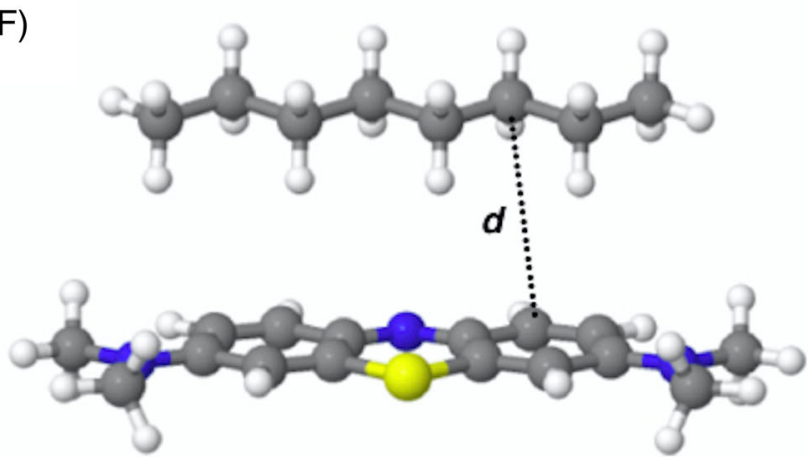

FIGURE 4 A, The electron density mapped with the electrostatic potential for a hydrated $\mathrm{MB}^{+}$cation. For the plotted density, $\rho=0.02$, the units range from $(-0.27,0.27)$ atomic units (a.u.). Regions with positive ESP (blue) have lower electron density than the regions with negative ESP (red). The most positive value in the ESP corresponds to the two hydrogen atoms next to the sulfur atom (yellow color). The hydrated $\mathrm{MB}^{+}$cation is electron deficient, with the hydrogen atoms and the aromatic rings having the lowest electron density. Snapshots from DFT calculations of a $B$, $\mathrm{MB}^{+}$-benzene dimer in $\pi-\pi$ stacking; $\mathrm{C}, \mathrm{D}$, E, dimers between $\mathrm{MB}^{+}$and $\mathrm{C}_{6} \mathrm{~F}_{6}$ featuring $\mathrm{H}$-bonds; $\mathrm{F}, \mathrm{MB}^{+}-\mathrm{C}_{8} \mathrm{H}_{18}$ dimer held by van der Waals interactions. Color scheme: fluorine green, hydrogen white, carbon dark gray, sulfur yellow, and nitrogen dark blue 


\section{2 | Prediction of adsorption of $\mathrm{MB}^{+}$}

Here, we detail our semiquantitative approach to predict the relative adsorption of $\mathrm{MB}^{+}$by our surrogate adsorbents. In order to make our model realistic, we added a water molecule in the coordination shell of $\mathrm{MB}^{+}$such that it had a binding energy of $E_{\mathrm{MB}^{+}} \cdot \mathrm{H}_{2} \mathrm{O}$. We chose that particular position of the water molecule, (Figure 3 ) because, therein, we obtained the strongest binding energy between the functional groups and $\mathrm{MB}^{+}$. We assumed that during adsorption this hydrogen bonded water molecule is displaced by the adsrobent. Figure 3 depicts this scheme with silica microspheres functionalized with $\mathrm{C}_{6} \mathrm{~F}_{6}$. The released water molecule simply becomes a part of the bulk water, releasing a fixed amount of energy, $E_{\mathrm{H}_{2} \mathrm{O}}$, which is half of the energy of a water dimer. Next, we define the adsorption energy between $\mathrm{MB}^{+}$and the adsorbent as,

$$
E_{\mathrm{b}}=E_{\text {dimer }}-\left(E_{\mathrm{MB}^{+}}+E_{\mathrm{adsb}}\right)
$$

and

$$
E_{\mathrm{ads}}=E_{\mathrm{b}}+E_{\mathrm{H}_{2} \mathrm{O}}-E_{\mathrm{MB}^{+} \cdot \mathrm{H}_{2} \mathrm{O}}
$$

where $E_{\mathrm{b}}$ is the binding energy of $\mathrm{MB}^{+}$and the adsorbent (after removing the explicit water molecule), $E_{\text {dimer }}$ is the electronic energy of the molecular complex ( $\mathrm{MB}^{+}$/adsorbent), $E_{\mathrm{MB}^{+}}$is the energy of a hydrated $\mathrm{MB}^{+}$cation, $E_{\mathrm{adsb}}$ is the energy of the adsorbent, $E_{\mathrm{ads}}$ is the adsorption energy that we use to calculate binding constants, and $E_{\mathrm{MB}^{+} . \mathrm{H}_{2} \mathrm{O}}$ is theenergy required to unbind the $\mathrm{MB}^{+} . \mathrm{H}_{2} \mathrm{O}$ dimer. It should be noted that $E_{\mathrm{b}}$ refers to the energy holding the $\mathrm{MB}^{+}$-adsorbent complex together, whereas $E_{\text {ads }}$ refers to the energy needed/released when displacing water from the $\mathrm{MB}$ coordination shell to form the $\mathrm{MB}^{+}$-adsorbent complex. We obtained a DFT binding energy for a water dimer using the PCM model at $0 \mathrm{~K}$ of $-5.4 \mathrm{kcal} \mathrm{mol}^{-1}$, which was in good agreement with the experimental results for water dimers in vacuum $\left.\left(-5.58 \mathrm{kcal}^{\mathrm{mol}}\right)^{-1}\right)^{[64]}$ and previous theoretical calculations $\left(-5.0 \mathrm{kcal} \mathrm{mol}^{-1}\right)^{[65]}$. Thus, $E_{\mathrm{H}_{2} \mathrm{O}}=-2.7 \mathrm{kcal} \mathrm{mol}^{-1},{ }^{[65]}$ and using the PCM method, we obtained the binding energy for $E_{\mathrm{MB}^{+} \cdot \mathrm{H}_{2} \mathrm{O}}=-1.4 \mathrm{kcal} \mathrm{mol}^{-1}$ (Figure S4, Data S3). With these predicted adsorption energies and assuming that, in our dilute solutions, only a single layer of $\mathrm{MB}^{+}$adsorbs onto the functionalized surface, we used the Arrhenius equation to calculate the relative reaction rate constants $(\mathrm{k})$ by taking as a reference the reaction rate constant for the $C_{8}$ aliphatic, $k_{\text {ref. }}$. We assume that the preexponential factor, $A$, in the Arrhenius equation is the same in all three cases and that the transition state barrier(s) that $\mathrm{MB}^{+}$has to overcome to bind to the surface are similar in magnitude in all the cases. This assumption is reasonable because the molecular interactions during the physisorption processes do not involve proton or electron transfers that would require covalent bond breaking/forming and significant electrostatic preorganization. ${ }^{[66]}$ Furthermore, we assume that thermal fluctuations $\left(0.6 \mathrm{kcal} \mathrm{mol}^{-1}\right)$ facilitate $\mathrm{MB}^{+}$, the solvent, and the surface to sample through the configurational space to find the global minima. Thus, we can estimate the relative binding rates as follows,

$$
\frac{k}{k_{\text {ref }}}=e^{-\left(\Delta E_{\text {ads }}\right)} k_{\mathrm{b}} T
$$

where $\Delta E_{\text {ads }}$ is the adsorption energy as defined in Equation (1) and relative to the adsorption energy of the $C_{8}$ aliphatic. A simple rearrangement of Equation (3) gives us the percentages of the relative rates of adsorption as,

$$
\frac{k-k_{\text {ref }}}{k_{\text {ref }}} \times 100=\left(e^{\left.-\left(\Delta E_{\text {ads }}\right) k_{\mathrm{b}} T-1\right) \times 100}\right.
$$

Next, we present the results of our DFT predictions for a variety of geometric confirmations between $\mathrm{MB}^{+}$and $\mathrm{C}_{6} \mathrm{~F}_{6}, \mathrm{C}_{6} \mathrm{H}_{6}$, and $\mathrm{C}_{8} \mathrm{H}_{18}$ groups, with the aim of identifying the relative contributions of $\pi-\pi$ stacking, hydrogen bonding (H-bonding), cation- $-\pi$ interactions, and van der Waals forces to the adsorption process (Table 1).

TA B LE 1 Predictions of adsorption energies, $E_{\text {ads }}$, for $\pi-\pi$ stacking, $\mathrm{H}$-bonding, and van der Waals interactions between $\mathrm{MB}^{+}$and $\mathrm{C}_{6} \mathrm{~F}_{6}, \mathrm{C}_{6} \mathrm{H}_{6}$, and $\mathrm{C}_{8} \mathrm{H}_{18}$ groups and the relative uptakes of $\mathrm{MB}^{+}$with the performance of n-octane taken as the reference

\begin{tabular}{llll}
\hline (Figure) Dimer & $\begin{array}{l}\text { Key molecular } \\
\text { interactions }\end{array}$ & $\begin{array}{l}\text { Adsorption energy, } \\
E_{\text {ads }}\left(\text { kcal mol }^{-1}\right)\end{array}$ & $\begin{array}{l}\text { Predicted, relative uptake } \\
\text { of } \mathrm{MB}^{+}(\%) \text { using Equation (4) }\end{array}$ \\
\hline (Figure 4B) $\mathrm{MB}^{+}-\mathrm{C}_{6} \mathrm{H}_{6}$ & $\pi-\pi$ stacking & -2.9 & 39 \\
\hline (Figure 4C) $\mathrm{MB}^{+}-\mathrm{C}_{6} \mathrm{~F}_{6}$ & $\mathrm{H}$-bond: $\mathrm{F}-\mathrm{H}$ (methyl), sided & -2.9 & 39 \\
\hline (Figure 4D) $\mathrm{MB}^{+}-\mathrm{C}_{6} \mathrm{~F}_{6}$ & $\mathrm{H}$-bond: $\mathrm{F}-\mathrm{H}$ (methyl) & -3.0 & 95 \\
\hline $\mathrm{C}_{6} \mathrm{~F}_{6}-\mathrm{MB}^{+}-\mathrm{C}_{6} \mathrm{~F}_{6}$ & $\mathrm{H}$-bond: $\mathrm{F}-\mathrm{H}$ (methyl) & -3.1 & 95 \\
\hline (Figure 4F) $\mathrm{MB}^{+}-\mathrm{C}_{8} \mathrm{H}_{18}$ & van der Waals & -2.7 & 0 (reference) \\
\hline
\end{tabular}




\section{3 $\quad \pi-\pi$ stacking between $\mathrm{MB}^{+}$and $\mathrm{C}_{6} \mathrm{H}_{6}$ and $\mathrm{C}_{6} \mathrm{~F}_{6}$ groups}

Benzene can donate electrons through its delocalized $\mathrm{p}_{\mathrm{z}}$ orbital to $\mathrm{MB}^{+}$in water. In fact, we found that the dimer $\mathrm{MB}^{+}-\mathrm{C}_{6} \mathrm{H}_{6}$ has a stable configuration in the $\pi-\pi$ stacking conformation (Figure 4B). The optimized structure has an average intermolecular distance, $d=4.8 \AA$, between (C $-\mathrm{C}$ ), indicating a weakly bound dimer. This result is in overall agreement with higher-level electronic structure methods such as MP2 and CCSD(T) for the $\pi-\pi$ benzene dimer, which shows an average intermolecular distance, $d$, in the range 3.8-4.1 $\AA^{[67]}$ We found that the adsorption energy was $E_{\text {ads }}=-2.9 \mathrm{kcal} \mathrm{mol}^{-1}$ (Table 1). Next, we substituted hydrogen atoms of benzene with fluorine atoms to simulate interactions of $\mathrm{MB}^{+}$with $\mathrm{C}_{6} \mathrm{~F}_{6}$. Fluorine has a deactivating effect on cation $-\pi$ interactions ${ }^{[17,68]}$ because electrons in $\mathrm{C}-\mathrm{F}$ bonds are polarized toward fluorine atoms due to the latter's higher electronegativity. ${ }^{[69]}$ Thus, $\mathrm{C}_{6} \mathrm{~F}_{6}$ is unlikely to interact with $\mathrm{MB}^{+}$through its $\pi$ orbitals. ${ }^{[26]}$ Thus, we expected $\pi-\pi$ stacking for the $\mathrm{MB}^{+}-\mathrm{C}_{6} \mathrm{~F}_{6}$ complex to be weaker than for the $\mathrm{MB}^{+}-\mathrm{C}_{6} \mathrm{H}_{6}$ complex. Indeed, this was true-while we arranged $\mathrm{C}_{6} \mathrm{~F}_{6}$ to interact with $\mathrm{MB}^{+}$through $\pi-\pi$ stacking, (Figure $4 \mathrm{~B}$ ), the $\mathrm{C}_{6} \mathrm{~F}_{6}$ molecule tilted over the $\mathrm{MB}^{+}$during geometry optimization and underwent a significant displacement. The final structure comprised an $\mathrm{MB}^{+}-\mathrm{C}_{6} \mathrm{~F}_{6}$ complex with hydrogen bonding between a fluorine atom and a hydrogen atom of $\mathrm{MB}^{+}$(Figure $4 \mathrm{C}$ ). The shortest distance between those atoms was, $d=3.1 \AA$, and the adsorption energy was $E_{\text {ads }}=-2.9 \mathrm{kcal} \mathrm{mol}^{-1}$.

\section{4 | Hydrogen bonding}

As $\mathrm{MB}^{+}$and $\mathrm{C}_{6} \mathrm{~F}_{6}$ interacted through $\mathrm{H}$-bonding instead of $\pi-\pi$ stacking, we investigated other configurations whereby $\mathrm{MB}^{+}$and $\mathrm{C}_{6} \mathrm{~F}_{6}$ were orientated facing each other. The final optimized structure had two $\mathrm{H}$-bonds,one between a fluorine atom and a hydrogen atom of a methyl group of $\mathrm{MB}^{+}$and another between a fluorine atom and a hydrogen atom bound to an $\mathrm{sp}^{2}$ carbon (Figure 4D). The shortest $\mathrm{F}-\mathrm{H}$ distance was $d=3.1 \AA$ with the dimer adsorption energy, $E_{\text {ads }}=-3.0 \mathrm{kcal} \mathrm{mol}^{-1}$. Surprisingly, although $\mathrm{C}_{6} \mathrm{~F}_{6}$ can interact with $\mathrm{MB}^{+}$through $\pi-\pi$ stacking, the overall low electron density of $\mathrm{MB}^{+}$and the presence of fluorine favored the formation of $\mathrm{H}$-bonds. It is worth noting that the adsorption energy also varied depending on the hybridization of the carbon atom; $\mathrm{C}\left(\mathrm{sp}^{3}\right)$ - $\mathrm{F}$ yielded a stronger hydrogen bond than $\mathrm{C}\left(\mathrm{sp}^{2}\right)$ - $\mathrm{F}$. ${ }^{[70]}$ Interestingly, even a $\pi$-electron donor like benzene yielded a lower $E_{\text {ads }}=-2.9 \mathrm{kcal} \mathrm{mol}^{-1}$ in comparison to the $\mathrm{H}$-bonded $\mathrm{C}_{6} \mathrm{H}_{6}-\mathrm{MB}^{+}$dimer with $E_{\text {ads }}=-3.0 \mathrm{kcal}$ mol ${ }^{-1}$. To further confirm the importance of the $\mathrm{H}$-bonding, we optimized two $\mathrm{C}_{6} \mathrm{~F}_{6}$ molecules with one $\mathrm{MB}^{+}$monomer. We found that, similar to the previous case, $\mathrm{C}_{6} \mathrm{~F}_{6}$ made $\mathrm{H}$-bonds with $\mathrm{MB}^{+}$(Figure 4E). Fluorine atoms in the $\mathrm{C}_{6} \mathrm{~F}_{6}$ groups formed $\mathrm{H}$-bonds with the methyl groups in $\mathrm{MB}^{+}$, but the shortest $\mathrm{H}$-bond distance was to the hydrogen next to the sulfur atom, $d=2.8 \AA$ and $E_{\text {ads }}=-3.1 \mathrm{kcal} \mathrm{mol}^{-1}$ (Figure $4 \mathrm{E}$ ). The adsorption energy was slightly greater than that of $\mathrm{MB}^{+}-\mathrm{C}_{6} \mathrm{~F}_{6}$, (Figure $4 \mathrm{D}$ ), indicating that increasing the number of $\mathrm{C}_{6} \mathrm{~F}_{6}$ species near $\mathrm{MB}^{+}$enhances the extent of adsorption. However, when we studied the $E_{\text {ads }}$ of $\mathrm{MB}^{+} .2\left(\mathrm{C}_{6} \mathrm{H}_{6}\right)$ in $\pi-\pi$ stacking conformation, we did not find any increment in the adsorption energy. (Figure S5, Data S3). Thus, only in the fluorinated case did we find that the most stable configuration was that with a ratio of 2:1. The study of 3:1 or higher configurations were computationally unfeasible or unable to converge.

\section{5 | Cation $-\pi$ interactions}

$\mathrm{MB}^{+}$is a large cation that could potentially interact with a $\pi$-system. In the gas phase, fluoroaromatic compounds are known to exhibit high binding energy with cations, for example, the ab initio binding energy of fluorobenzene with a lithium ion is $E_{\mathrm{b}}=-31 \mathrm{kcal} . \mathrm{mol}^{-1 .[71]} \mathrm{However}$, for $\mathrm{MB}^{+}$ interacting with $\mathrm{C}_{6} \mathrm{~F}_{6}$ in an aqueous environment, we did not find dimer configurations stabilized by cation- $\pi$ interactions (Figure S6, Data S3). The final optimized structures between $\mathrm{MB}^{+}$and $\mathrm{C}_{6} \mathrm{~F}_{6}$ comprised $\mathrm{H}$-bonds between $\mathrm{F}$ and $\mathrm{H}$ atoms similar to those seen in Figure $4 \mathrm{~B}$, with similar binding energy and $\mathrm{H}$-bond distances. Thus, $\mathrm{C}_{6} \mathrm{~F}_{6}-\mathrm{MB}^{+}$dimers optimized from the initial configurations of $\pi-\pi$ stacking or cation- $-\pi$ stacking were not stable, and the optimized structures always led to dimers interacting through $\mathrm{H}$-bonding. Furthermore, $\mathrm{C}_{6} \mathrm{H}_{6}-\mathrm{MB}^{+}$did not demonstrate configurations stabilized by cation $-\pi$ interactions or hydrogen bonding (only $\pi-\pi$ stacking).

\section{6 | Van der Waals interactions}

Finally, we investigated the interactions between the aliphatic chain $\mathrm{C}_{8} \mathrm{H}_{18}$ and $\mathrm{MB}^{+}$in an aqueous solution. We found that $E_{\text {ads }}=-2.7 \mathrm{kcal}$ mol ${ }^{-1}$, and the interaction was driven by van der Waals dispersion forces. ${ }^{[27]}$ The average intermolecular distance $d=3.2 \AA$ (Figure 4F).

\subsection{A comparison of various intermolecular forces}

Based on the predictions from quantum mechanics, we listed the $E_{\text {ads }}$ values due to different molecular interactions in Table 1. We used Equation (4) to predict the trend in the binding constants of the three functional groups, $\mathrm{C}_{6} \mathrm{~F}_{6}(\mathrm{H}-$-bonding $)>\mathrm{C}_{6} \mathrm{H}_{6}(\pi-\pi$ stacking and 
$\mathrm{H}$-bonding) $>\mathrm{C}_{8} \mathrm{H}_{18}$ (vdW dispersion). To obtain quantitative insights, we benchmarked the binding constants against the aliphatic group ( $\mathrm{C}_{8} \mathrm{H}_{18}$ ) and found the relative adsorption to vary such that $\mathrm{C}_{6} \mathrm{~F}_{6}(95 \%)>\mathrm{C}_{6} \mathrm{H}_{6}(39 \%)>\mathrm{C}_{8} \mathrm{H}_{18}(0)$, which was an unexpected result. Next, we tested our predictions through laboratory experiments.

\subsection{Experimental adsorption of $\mathrm{MB}^{+}$on an organic substrate}

We designed laboratory experiments to test our predictions, ie, $\mathrm{H}$-bonding between $\mathrm{MB}^{+}$and $\mathrm{C}_{6} \mathrm{~F}_{6}$ leads to a dramatically higher adsorption than that due to $\pi-\pi$ stacking between $\mathrm{MB}^{+}$and $\mathrm{C}_{6} \mathrm{H}_{6}$ or van der Waals interactions between $\mathrm{MB}^{+}$and $\mathrm{C}_{8} \mathrm{H}_{18}$. To this end, we functionalized hollow silica microspheres with $-\mathrm{C}_{8} \mathrm{H}_{17},-\mathrm{C}_{6} \mathrm{H}_{5}$, and $-\mathrm{C}_{6} \mathrm{~F}_{5}$ moieties (Section 2.2). We employed attenuated total reflectance-Fourier transform infrared (ATR-FTIR) spectroscopy to characterize the silica microspheres before and after functionalization (Figure S2). We found the following signatures for the molecular vibrations of the functional groups: $\mathrm{Si}-\mathrm{C}_{8} \mathrm{H}_{17}$ : asymmetric and symmetric $\mathrm{CH}_{2}$ vibrations around $2922 \mathrm{~cm}^{-1}$ and $2852 \mathrm{~cm}^{-1}$ respectively; $\mathrm{Si}-\mathrm{C}_{6} \mathrm{~F}_{5}: \mathrm{C}=\mathrm{C}$ and $\mathrm{C}-\mathrm{F}$ aromatic stretching bands at $1424 \mathrm{~cm}^{-1}$ and $1662 \mathrm{~cm}^{-1}$, respectively; and $\mathrm{Si}-\mathrm{C}_{6} \mathrm{H}_{5}$ : $\mathrm{C}-\mathrm{H}$ stretch bands at $3074 \mathrm{~cm}^{-1}$ and $3052 \mathrm{~cm}^{-1}$ and $\mathrm{C}-\mathrm{C}$ stretch (in-ring) at $1624 \mathrm{~cm}^{-1}$ and $1434 \mathrm{~cm}^{-1}$ (Data S1.2). Crucially, the apparent contact angles of water droplets on glass slides silanized with $-\mathrm{C}_{6} \mathrm{~F}_{5},-\mathrm{C}_{6} \mathrm{H}_{5}$, and $-\mathrm{C}_{8} \mathrm{H}_{17}$ groups were similar, which led us to expect that their uptake of $\mathrm{MB}^{+}$might be similar in magnitude (Data S1.3, Figure S3, and Table S1). This expectation was based on the extant literature on the adsorption of simple and complex organics onto hydrophobic surfaces in water-organic fouling-a leading cause for the failure of membrane-based separation technologies. ${ }^{[58,72-75]}$ We also note that $\xi$-potentials of hydrocarbon and perfluorocarbon surfaces, which have been investigated extensively in the past and intensely debated on regarding their influence on interfacial charges, wetting, surface forces, and adsorption. ${ }^{[4,76-78]}$ However, it was not possible to measure $\xi$-potentials of our specific samples because of their buoyancy and hydrophobicity; they would not stay inside a water-filled cuvette.

To compare the uptakes of $\mathrm{MB}^{+}$by silica microspheres, we measured the UV-VIS absorbance spectra of 100 -ppm aqueous solutions of $\mathrm{MB}^{+}$. The trend was as follows: $\mathrm{Si}-\mathrm{C}_{6} \mathrm{H}_{5}(95 \% \pm 1.8 \%)>\mathrm{Si}-\mathrm{C}_{6} \mathrm{H}_{5}(35 \% \pm 1.9 \%)>\mathrm{Si}-\mathrm{C}_{8} \mathrm{H}_{17}(3 \% \pm 2.5 \%)$ (Figure 5). The alkyl derivative $\mathrm{Si}-\mathrm{C}_{8} \mathrm{H}_{17}$ barely adsorbed any $\mathrm{MB}^{+}$, the perfluorinated benzene performed the best, and the benzene-terminated microspheres performed intermediately, according to the predictions.

We also performed the elemental analysis of the relative carbon contents of the functionalized silica beads, from the functional groups on the surfaces, and found no correlation between the amount of carbon and the extent of adsorption (see Data S1.4, Table S2). Thus, the dramatically different adsorption levels of $\mathrm{MB}^{+}$onto the functional groups were due to different intermolecular forces at play. After these experiments, the beads could be easily removed from the air-water interface as they floated up. We are currently developing greener methodologies for regenerating them that will be reported soon. Figure 6 summarizes this report.

The advantage of this approach relies on the calculation of relative electronic energies to study adsorption at solid-liquid interfaces. We have simplified the complex molecular representation of the functionalized (solid) surfaces by individual (functional) molecules. Of course, this approach has limitations, for instance, the use of free energies (thermal correction) instead of electronic energies at $0 \mathrm{~K}$ might be more accurate. However, as the adsorption energy is relatively proportional to the total electronic energy, the addition of the free energy contribution should not alter the predicted trends significantly. Furthermore, the incorporation of vibrational frequencies into our energy calculations would be misleading because the individual (functional) molecules would behave more like a liquid that, in comparison to the solid phase, possesses extra rotational degrees of
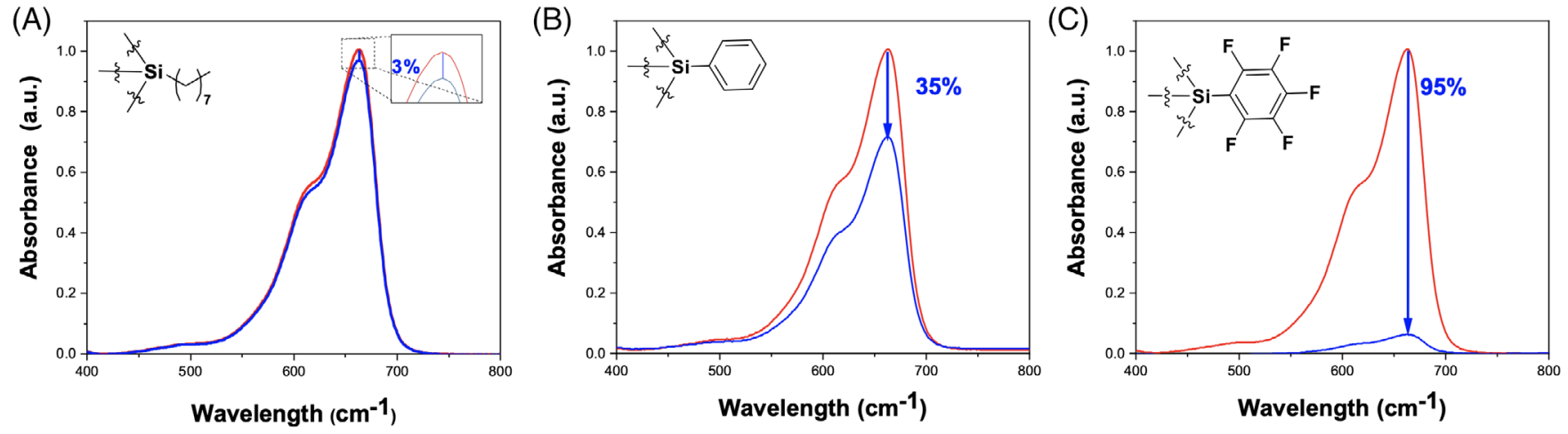

FIGURE 5 Absorbance spectra obtained after treating 20-mL $\mathrm{MB}^{+}$solutions (initial concentration: $100 \mathrm{ppm}$ ) with $100 \mathrm{mg}$ of silica microspheres functionalized with: $\mathrm{A}, \mathrm{Si}-\mathrm{C}_{8} \mathrm{H}_{17} ; \mathrm{B}, \mathrm{Si}-\mathrm{C}_{6} \mathrm{H}_{5}$; and $\mathrm{C}, \mathrm{Si}-\mathrm{C}_{6} \mathrm{~F}_{5} . \mathrm{MB}^{+}$absorbance in the solution after incubation followed this trend: $\mathrm{Si}-\mathrm{C}_{6} \mathrm{H}_{5}(95 \% \pm 1.8 \%)>\mathrm{Si}-\mathrm{C}_{6} \mathrm{H}_{5}(35 \% \pm 1.9 \%)>\mathrm{Si}-\mathrm{C}_{8} \mathrm{H}_{17}(3 \% \pm 2.5 \%)$. In all the cases, the operational pH was 6.8; all experiments were repeated at least in quadruplicates 


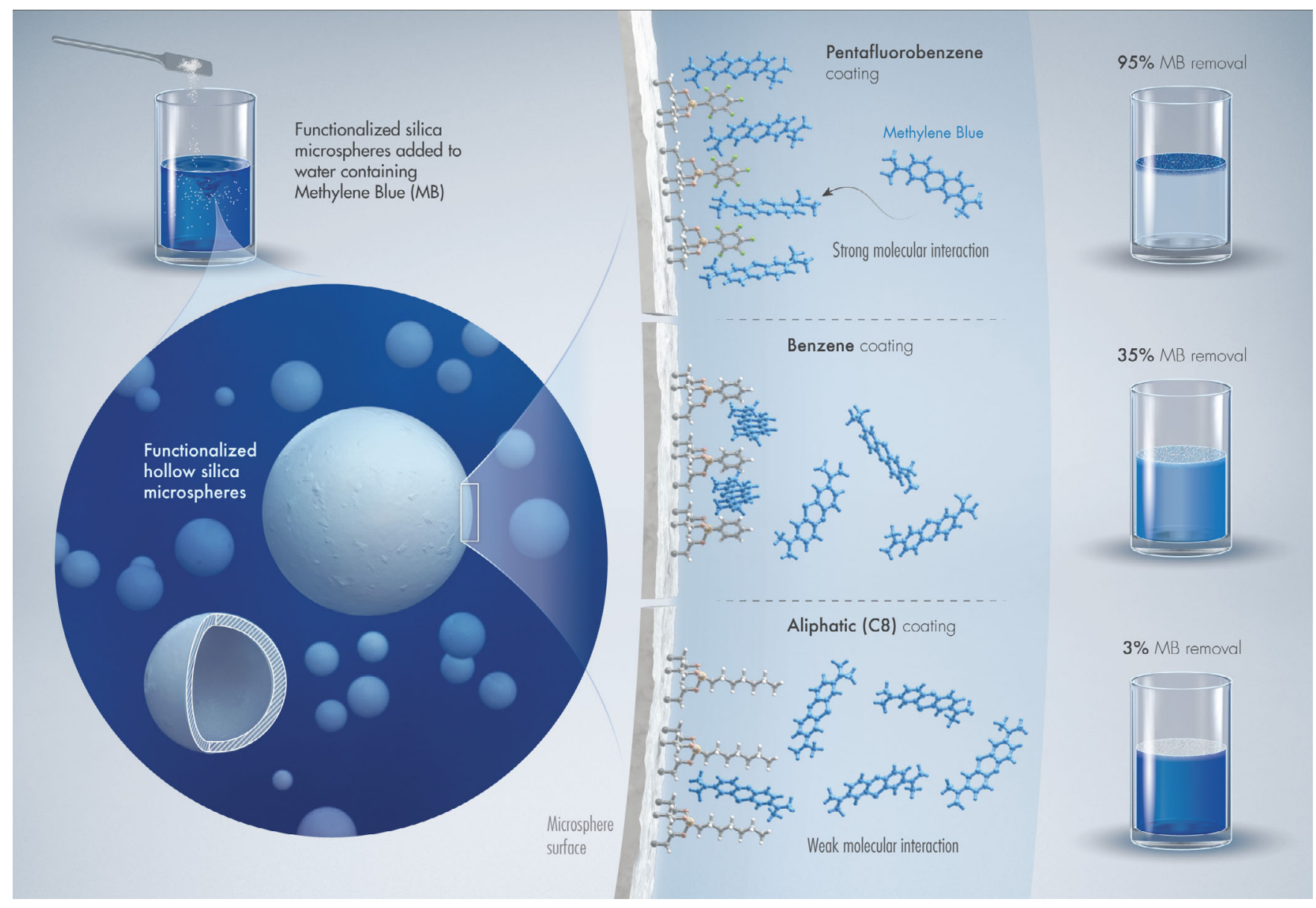

FIGURE 6 Summary of laboratory experiments. (Left panel) Hollow silica microspheres functionalized with $-\mathrm{C}_{6} \mathrm{~F}_{5},-\mathrm{C}_{6} \mathrm{H}_{5}$, and $-\mathrm{C}_{8} \mathrm{H}_{17}$ groups were added to water containing $100 \mathrm{ppm} \mathrm{MB}^{+}$. (Middle panel) Intermolecular interactions between the silanized silica surfaces and $\mathrm{MB}^{+}$ ions in water (Right panel). The final outcome of our simulated water treatment experiments: Pentafluorobenzene performed the best, followed by benzene and the aliphatic group as follows: $\mathrm{C}_{6} \mathrm{~F}_{5}(95 \% \pm 1.8 \%)>\mathrm{Si}-\mathrm{C}_{6} \mathrm{H}_{5}(35 \% \pm 1.9 \%)>\mathrm{Si}-\mathrm{C}_{8} \mathrm{H}_{17}$

freedom. Despite these limitations, the model predictions are in excellent agreement with experimental observations and should be extendible toward the development of rational treatment protocols for other wastewaters.

\section{4 | CONCLUSION}

Towards rationally designing reusable adsorbents for complex contaminants in wastewater streams, such as from textile, cosmetics, pulp and paper, food and beverages, packaging, paints, and pharmaceutical industries, we investigated molecular interactions of $\mathrm{MB}^{+}$with $\mathrm{C}_{6} \mathrm{~F}_{6}, \mathrm{C}_{6} \mathrm{H}_{6}$, and $\mathrm{C}_{8} \mathrm{H}_{18}$ groups as surrogate adsorbents. DFT was employed with the Polarizable Continuum Model to accurately determine the contributions of the solvent's electrostatics during adsorption. Model calculations predicted that the primary intermolecular interactions of $\mathrm{MB}^{+}$with these functional groups were hydrogen bonding between $\mathrm{MB}^{+}$and $\mathrm{C}_{6} \mathrm{~F}_{6} ; \pi-\pi$ stacking between $\mathrm{C}_{6} \mathrm{H}_{6}$ and $\mathrm{MB}^{+}$; and van der Waals dispersion interactions between $\mathrm{C}_{8} \mathrm{H}_{18}$. Based on this, the relative magnitudes of the predicted binding constants for $\mathrm{MB}^{+}$were: $\mathrm{C}_{6} \mathrm{~F}_{6}(95 \%)>\mathrm{C}_{6} \mathrm{H}_{6}(39 \%)>\mathrm{C}_{8} \mathrm{H}_{18}(0)$. Thus, DFT predicted that fluorinated aromatics are more suitable for removing $\mathrm{MB}^{+}$from water than ordinary aromatics and hydrocarbons. Gaining these molecular insights from an exclusively experimental approach would be very difficult. For instance, one cannot predict the observed behaviors based on water contact angles, which are often used to assess surfaces' ability to aggregate organics in water by hydrophobic interactions. ${ }^{[79]}$ Indeed, our laboratory experiments with functionalized silica microspheres confirmed the predicted trends: $\mathrm{Si}-\mathrm{C}_{6} \mathrm{~F}_{5}(95 \% \pm 1.8 \%)>$ $\mathrm{Si}-\mathrm{C}_{6} \mathrm{H}_{5}(35 \% \pm 1.9 \%)>\mathrm{Si}-\mathrm{C}_{8} \mathrm{H}_{17}(3 \% \pm 2.5 \%)$. Thus, this report illustrates that a clear understanding of intermolecular forces is crucial in designing adsorbents for complex wastewater contaminants, such as dyes. This approach can thus be extended to anionic/zwitterionic/uncharged dyes, other wastewater contaminants, and also for finding greener and fouling-resistant materials/approaches. ${ }^{\text {[0-85] }}$ Taken together, our findings suggest that this first-principles approach, supported by laboratory experiments, for the rational design of functional materials in the treatment of wastewaters can contribute to the sustainable use of water. 


\section{ACKNOWLEDGMENTS}

This research used the resources of the Supercomputing Laboratory at King Abdullah University of Science and Technology (KAUST) in Thuwal, Saudi Arabia. The authors thank Mr Xavier Pita, Scientific Illustrator at KAUST, for preparing Figure 6 and Dr Michael Cusack (KAUST) for scientific editing. The authors gratefully acknowledge discussions with Dr Riccarda Caputto (ETH, Zurich) and Dr Tod Pascal (University of California San Diego) at, respectively, the beginning and end of this project. Himanshu Mishra acknowledges KAUST for funding (Grant \#BAS/1/1070-01-01).

\section{AUTHOR CONTRIBUTIONS}

Adriano Santana: Conceptualization; investigation; data curation; formal analysis; writing-review and editing. Andreia Farinha: Conceptualization; investigation; validation; data curation; project administration; writing-review and editing. Aniela Torano: Investigation; Data curation; writingreview and editing. Mahmoud Ibrahim: Methodology; validation. Himanshu Mishra: Conceptualization; data curation; formal analysis; funding acquisition; investigation; methodology; project administration; resources; supervision; writing-original draft; writing-review and editing.

\section{ORCID}

Himanshu Mishra (D) https://orcid.org/0000-0001-8759-7812

\section{REFERENCES}

[1] HLPE, 2015. Water for Food security and nutrition. A report by the High Level Panel of Experts on Food Security and Nutrition of the Committee on World Food Security, Rome 2015.

[2] FAO. The Future of Food and Agriculture: Trends and Challenges; 2017.

[3] M. Rodell, J. Famiglietti, D. Wiese, J. Reager, H. Beaudoing, F. W. Landerer, M.-H. Lo, Nature 2018, 557(7707), 651.

[4] M. P. Yutkin, H. Mishra, T. W. Patzek, J. Lee, C. J. Radke, SPE J. 2018, 23, 84.

[5] United Nations World Water Assessment Programme/UN-Water. 2018. The United Nations World Water Development Report 2018: Nature-Based Solutions for Water. Paris, UNESCO.

[6] L. T. Angenent, K. Karim, M. H. Al-Dahhan, B. A. Wrenn, R. Domíguez-Espinosa, Trends Biotechnol. 2004, $22(9), 477$.

[7] United Nations World Water Assessment Programme. 2017. The United Nations World Water Development Report 2017. Wastewater: The Untapped Resource. Paris, UNESCO.

[8] K. P. Katuri, S. Kalathil, A. Ragab, B. Bian, M. F. Alqahtani, D. Pant, P. E. Saikaly, Adv Mater 2018, 30(26), 1707072.

[9] W. R. Stahel, Nature 2016, 531(7595), 435.

[10] S. Jiménez, M. Micó, M. Arnaldos, F. Medina, S. Contreras, Chemosphere 2018, 192, 186.

[11] P.-Y. Hong, T. Julian, M.-L. Pype, S. Jiang, K. Nelson, D. Graham, A. Pruden, C. Manaia, Water 2018, 10(3), 244.

[12] M. T. Yagub, T. K. Sen, S. Afroze, H. M. Ang, Adv Colloid Interface Sci. 2014, 209, 172.

[13] Z. Salahshoor, A. Shahbazi, Eur. J. Environ. Sci. 2014, 4(2), 116.

[14] T. Robinson, G. McMullan, R. Marchant, P. Nigam, Bioresour. Technol. 2001, 77(3), 247.

[15] A. Gürses, M. Açıkyıldız, K. Güneş, M. S. Gürses, Dyes and pigments: their structure and properties. in Dyes and Pigments, Springer, Switzerland 2016, p. 13.

[16] M. K. Purkait, A. Maiti, S. Dasgupta, S. De, J. Hazard. Mater. 2007, 145(1-2), 287.

[17] D. A. Dougherty, Acc. Chem. Res. 2012, 46(4), 885.

[18] T. Sato, T. Tsuneda, K. Hirao, J. Chem. Phys. 2005, 123(10), 104307.

[19] J. N. Israelachvili, Intermolecular and Surface Forces, 3rd ed. (Revised), Academic Press, Waltham, MA 2011.

[20] B. Bera, N. Shahidzadeh, H. Mishra, L. A. Belyaeva, G. F. Schneider, D. Bonn, Appl. Phys. Lett. 2018, 112(15), 151606.

[21] K. W. Whitten, R. E. Davis, L. Peck, G. G. Stanley, General Chemistry (Pg 486, Table 13-3), 7th ed., Cengage Learning, Boston 2003 , p. 1224.

[22] K. S. Lackner, Energy 2013, 50, 38.

[23] H. Mishra, C. Yu, D. P. Chen, W. A. Goddard III., N. F. Dalleska, M. R. Hoffmann, M. S. Diallo, Environ. Sci. Technol. 2012, $46(16), 8998$.

[24] J. L. Mendoza-Cortés, S. S. Han, H. Furukawa, O. M. Yaghi, W. A. Goddard III., J. Phys. Chem. A 2010, 114(40), 10824.

[25] H. Berneth, Ullmann's Encyclopedia of Industrial Chemistry, Chapter: Azine Dyes, 2012, Vol. 4, pp. 475-514, Wiley, Weinheim.

[26] J. P. Gallivan, D. A. Dougherty, Org. Lett. 1999, 1(1), 103.

[27] L. Zhou, R. Johnson, T. Habteyes, H. Guo, J. Chem. Phys. 2017, 146(16), 164701.

[28] A. Delport, B. H. Harvey, A. Petzer, J. P. Petzer, Metab. Brain Dis. 2017, 32(5), 1357.

[29] A. F. dos Santos, L. F. Terra, R. A. Wailemann, T. C. Oliveira, V. de Morais Gomes, M. F. Mineiro, F. C. Meotti, A. Bruni-Cardoso, M. S. Baptista, L. Labriola, BMC Cancer 2017, 17(1), 194.

[30] P. E. Meissner, G. Mandi, B. Coulibaly, S. Witte, T. Tapsoba, U. Mansmann, J. Rengelshausen, W. Schiek, A. Jahn, I. Walter-Sack, Malar. J. 2006, 5 (1), 84.

[31] H. Atamna, R. Kumar, J. Alzheimer's Dis. 2010, 20(s2), S439.

[32] Z.-M. Xiong, M. O'Donovan, L. Sun, J. Y. Choi, M. Ren, K. Cao, Sci. Rep. 2017, 7(1), 2475.

[33] A. De Keizer, L. Fokkink, Colloids Surf. A 1990, 51, 323.

[34] J. A. Pople, P. M. Gill, N. C. Handy, Int. J. Quantum Chem. 1995, 56(4), 303.

[35] W. Kohn, L. J. Sham, Phys. Rev. 1965, 140(4A), A1133.

[36] W. Koch, M. C. Holthausen, A Chemist's Guide to Density Functional Theory, John Wiley \& Sons, Weinheim, Germany 2015.

[37] S. Grimme, J. Antony, T. Schwabe, C. Mück-Lichtenfeld, Org. Biomol. Chem. 2007, 5(5), 741.

[38] J. M. Pérez-Jordá, A. D. Becke, Chem. Phys. Lett. 1995, 233(1-2), 134. 
[39] S. Grimme, J. Antony, S. Ehrlich, H. Krieg, J. Chem. Phys. 2010, 132(15), 154104.

[40] A. Becke, J. Chem. Phys. 1993, 98(5), 648.

[41] J. A. Plumley, J. Dannenberg, J. Comput. Chem. 2011, 32(8), 1519.

[42] Y.-f. Chen, J. Dannenberg, J. Am. Chem. Soc. 2006, 128(25), 8100.

[43] V. S. Bryantsev, M. S. Diallo, A. C. Van Duin, W. A. Goddard III., J. Chem. Theory Comput. 2009, 5(4), 1016.

[44] H. Mishra, S. Enami, R. J. Nielsen, L. A. Stewart, M. R. Hoffmann, W. A. Goddard, A. J. Colussi, Proc. Natl. Acad. Sci. USA 2012, $109(46), 18679$.

[45] H. Mishra, R. J. Nielsen, S. Enami, M. R. Hoffmann, A. J. Colussi, W. A. Goddard, Int. J. Quantum Chem. 2013, 113(4), 413.

[46] H. Mishra, S. Enami, R. J. Nielsen, M. R. Hoffmann, W. A. Goddard, A. J. Colussi, Proc. Natl. Acad. Sci. USA 2012, $109(26), 10228$.

[47] A. Gallo, A. S. Farinha, M. Dinis, A.-H. Emwas, A. Santana, R. J. Nielsen, W. A. Goddard, H. Mishra, Chem. Sci. 2019, $10(9), 2566$.

[48] A. J. Colussi, S. Enami, A. Yabushita, M. R. Hoffmann, W.-G. Liu, H. Mishra, W. A. Goddard III., Faraday Discuss. 2013, $165,407$.

[49] A. Gallo, A. S. F. Farinha, A.-H. Emwas, A. Santana, R. J. Nielsen, W. A. Goddard, H. Mishra, Chem. Sci. 2019, 10, 8256. https://doi.org/10.1039/ c9sc00991d.

[50] H. Shi, S. M. Auerbach, A. Ramasubramaniam, J. Phys. Chem. C 2016, 120(22), 11899.

[51] J. H. Jensen, Phys. Chem. Chem. Phys. 2015, 17(19), 12441.

[52] G. Raja, K. Saravanan, S. Sivakumar, Comp. Chem. 2011, 32, 2111.

[53] D. E. Taylor, J. G. Ángyán, G. Galli, C. Zhang, F. Gygi, K. Hirao, J. W. Song, K. Rahul, O. von Anatole Lilienfeld, R. Podeszwa, I. W. Bulik, T. M. Henderson, G. E. Scuseria, J. Toulouse, R. Peverati, D. G. Truhlar, K. Szalewicz, J. Chem. Phys. 2016, 145(12), 124105.

[54] N. Mardirossian, M. Head-Gordon, J. Chem. Phys. 2016, 145(18), 186101.

[55] J. Tomasi, B. Mennucci, R. Cammi, Chem. Rev. 2005, 105(8), 2999.

[56] M. Frisch, G. Trucks, H. B. Schlegel, G. Scuseria, M. Robb, J. Cheeseman, G. Scalmani, V. Barone, B. Mennucci, G. Petersson, Gaussian 09, Revision A. 02, Gaussian Inc., Wallingford, CT 2009 200, 28.

[57] O. Lingk. 3M Glass Bubbles: Lightweight Compounds and Composites Based on High Strength Hollow Glass Microspheres. https://www.b2match.eu/ system/nl-nrw2016/files/3M_Germany.pdf?1456150121.

[58] N. Subramanian, A. Qamar, A. Alsaadi, A. Gallo, M. G. Ridwan, J.-G. Lee, S. Pillai, S. Arunachalam, D. Anjum, F. Sharipov, N. Ghaffour, H. Mishra, J. Colloid Interface Sci. 2019, 533, 723.

[59] H. Mishra, A. S. Farinha, S. Sinha. US20180250656A1; 2016.

[60] A. Leach, Molecular Modeling Principles and Applications, 2nd ed., Pearson Education Limited, Harlow, England 2001.

[61] J. S. Murray, P. Politzer, Wiley Interdiscip. Rev.: Comput. Mol. Sci. 2011, 1(2), 153.

[62] F. Jensen, Introduction to Computational Chemistry, John Wiley \& Sons, Chichester, UK 2017.

[63] R. Dennington, T. Keith, J. G. Millam, GaussView version 5, Semichem Inc., Shawnee Mission, KS 2009.

[64] S. Suresh, V. Naik, J. Chem. Phys. 2000, 113(21), 9727.

[65] M. W. Feyereisen, D. Feller, D. A. Dixon, J. Phys. Chem. 1996, 100(8), 2993.

[66] S. C. L. Kamerlin, A. Warshel, Proteins: Struct., Funct., Bioinf. 2010, 78(6), 1339.

[67] M. O. Sinnokrot, E. F. Valeev, C. D. Sherrill, J. Am. Chem. Soc. 2002, 124(36), 10887.

[68] S. Mecozzi, A. P. West, D. A. Dougherty, J. Am. Chem. Soc. 1996, 118(9), 2307.

[69] L. Pauling, J. Am. Chem. Soc. 1932, 54(9), 3570.

[70] J. A. Howard, V. J. Hoy, D. O'Hagan, G. T. Smith, Tetrahedron 1996, 52(38), 12613.

[71] A. V. Razgulin, S. Mecozzi, J. Med. Chem. 2006, 49(26), 7902.

[72] C. Liu, L. Chen, L. Zhu, J. Membr. Sci. 2018, 548, 125.

[73] G. Naidu, S. Jeong, S. Vigneswaran, T.-M. Hwang, Y.-J. Choi, S.-H. Kim, Desalin. Water Treat. 2016, 57(22), 10052.

[74] M. Rezaei, D. M. Warsinger, M. C. Duke, T. Matsuura, W. M. Samhaber, Water Res. 2018, 139, 329.

[75] R. Das, S. Arunachalam, Z. Ahmad, E. Manalastas, H. Mishra, J. Membr. Sci. 2019, 588, 117185.

[76] J. K. Beattie, Lab Chip 2006, 6(11), 1409.

[77] L. S. McCarty, G. M. Whitesides, Angew. Chem. Int. Ed. 2008, 47(12), 2188.

[78] J. Nauruzbayeva, Z. Sun, A. Gallo Jr., M. Ibrahim, C. J. Santamarina, H. Mishra, Nature Comm., 2020, https://doi.org/10.1038/s41467-020-19054-8 (in press).

[79] B. R. Shrestha, S. Pillai, A. Santana, S. H. Donaldson Jr., T. A. Pascal, H. Mishra, J. Phys. Chem. Lett. 2019, 10, 5530.

[80] E. M. Domingues, S. Arunachalam, J. Nauruzbayeva, H. Mishra, Nat. Commun. 2018, 9(1), 3606.

[81] E. M. Domingues, S. Arunachalam, H. Mishra, ACS Appl. Mater. Inter. 2017, 9(25), 21532.

[82] S. R. Gonzalez-Avila, D. M. Nguyen, S. Arunachalam, E. M. Domingues, H. Mishra, C.-D. Ohl, Sci. Adv. 2020, 6(13), eaax6192.

[83] S. Pillai, A. Santana, R. Das, B. R. Shrestha, E. Manalastas, H. Mishra, J. Membr. Sci. 2020, 608, 118140.

[84] S. Arunachalam, Z. Ahmad, R. Das, H. Mishra, Advanced Materials Interfaces, https://doi.org/10.1002/admi.202001268 (in press).

[85] R. Das, Z. Ahmad, J. Nauruzbayeva, H. Mishra, Sci. Rep. 2020, 10(1), 7934.

\section{SUPPORTING INFORMATION}

Additional supporting information may be found online in the Supporting Information section at the end of this article.

How to cite this article: Santana A, Farinha ASF, Toraño AZ, Ibrahim M, Mishra H. A first-principles approach for treating wastewaters. Int J Quantum Chem. 2020;e26501. https://doi.org/10.1002/qua.26501 